ORIGINAL ARTICLE

\title{
A Review of Cases of Human Cysticercosis in Canada
}

\author{
Oscar H. Del Brutto
}

\begin{abstract}
Objective: Review of human cysticercosis in Canada, to estimate the magnitude of the disease and to describe the pattern of disease expression in this country. Methods: MEDLINE and manual search of case reports and case series of patients with cysticercosis diagnosed in Canada. Abstracted data included year of diagnosis, citizenship status, clinical manifestations, and form of cysticercosis. Findings: A total of 21 articles reporting 60 patients were found. Forty (67\%) of these patients were diagnosed in the past two decades. Most cases came from Ontario $(n=43)$ and Quebec $(n=14)$. Immigrants accounted for $96 \%$ of the 28 cases in whom citizenship information was available. Neurocysticercosis was observed in 55 patients, and isolated compromise of striated muscles in the remaining five. Seizures was the primary or sole manifestation of the disease in $72 \%$ of patients, and most of them had parenchymal brain cysticerci (either viable cysts or calcifications). Two of seven patients were positive for Taenia eggs. In no case were household contacts of the patients investigated for taeniasis. Conclusions: An increasing number of patients with cysticercosis have been reported from Canada in the past two decades, suggesting that the prevalence of this parasitic disease may be on the rise. While most cases occur in immigrants, it is possible that at least some of these patients had acquired the disease in Canada.
\end{abstract}

RÉSUMÉ: Revue des cas de cysticercose chez l'humain au Canada. Objectif : Nous avons effectué une revue des cas de cysticercose chez l'humain au Canada afin d'estimer l'ampleur et de décrire les manifestations cliniques de la maladie dans ce pays. Méthode : Nous avons effectué une recherche dans MEDLINE, ainsi que manuellement, d'observations cliniques et de séries de patients atteints de cysticercose diagnostiqués au Canada. Nous avons colligé l'année du diagnostic, la citoyenneté, les manifestations cliniques et le type de cysticercose. Constatations : Nous avons identifié 21 articles qui portaient en tout sur 60 patients. Quarante (67\%) de ces patients ont été diagnostiqués au cours des deux dernières décennies, dont 43 en Ontario et 14 au Québec. Parmi les 28 patients dont la citoyenneté était mentionnée, 96\% étaient des immigrants. Cinquante-cinq patients étaient atteints de neurocysticercose et les cinq autres avaient une atteinte isolée des muscles striés. Chez $72 \%$ des patients, des crises convulsives étaient la principale ou la seule manifestation de la maladie et la plupart d'entre eux étaient porteurs de cysticerques (soit des kystes viables ou des calcifications). Le test de détection des œufs de ténia était positif chez 2 des 7 patients qui ont subi le dépistage de la téniase. Le dépistage de la téniase n'a pas été fait chez les proches de ces patients. Conclusions : Un nombre croissant de cas de cysticercose ont été rapportés au Canada depuis une vingtaine d'années, ce qui est compatible avec une prévalence croissante de cette parasitose. Bien que la plupart des cas se retrouvent parmi les immigrants, il est possible qu'un certain nombre de patients aient été contaminés au Canada.

Can J Neurol Sci. 2012; 39: 319-322

Cysticercosis is the most common helminthic infection of the nervous system, and a leading cause of acquired epilepsy worldwide $^{1}$. The disease occurs when humans become intermediate hosts of the tapeworm Taenia solium by ingesting its eggs from contaminated food or, most often, directly from a taenia carrier (fecal-oral route). Within the nervous system, parasites may be located in brain parenchyma, subarachnoid space, ventricular system, or spinal cord, causing a myriad of pathological changes that are mainly responsible for the clinical pleomorphism of neurocysticercosis.

Cysticercosis is endemic in most of the developing world. There, millions of people are infected by this parasite, and many of them - at any point of their lives - will experience the clinical consequences of this infection ${ }^{2}$. In general terms, human cysticercosis was rare in developed countries up to 30 years ago. Together with the growing number of immigrants from endemic areas, there has been an increase in the number of patients with cysticercosis in these countries. In the US, most cases have been reported from the Southwestern States where more than 20 million Mexican-Americans live. Almost $90 \%$ of these patients are immigrants from Mexico or South America ${ }^{3,4}$. A similar scenario has been observed in some European countries, where mass immigration of people from South America has caused a recent increase in the prevalence of this parasitic disease ${ }^{5}$.

While swine cysticercosis was recognized in Canada by Sir William Osler during the 19th Century ${ }^{6}$, the situation of human cysticercosis in this country is largely unknown, probably because of under-reporting of existing cases or the lack of epidemiological studies attempting to determine the prevalence of this parasitic disease. The main purpose of this study is to present a review of the literature on human cysticercosis in Canada, to estimate the magnitude of the disease and to describe the pattern of disease expression in this country.

From the Department of Neurological Sciences, Hospital-Clínica Kennedy, Guayaquil, Ecuador.

Received October 27, 2011. Final Revisions Submitted November 29, 2011. Correspondence to: Oscar H. Del Brutto, Air Center 3542, PO Box 522970, Miami, Florida, 33152-2970, USA. Email: oscardelbrutto@ hotmail.com 


\section{METHODS}

A literature search of human cysticercosis in Canada was performed using the electronic database of MEDLINE (National Library of Medicine, Bethesda, MD). Key words "Cysticercosis" and "Neurocysticercosis" were combined with "Canada". Limits were not applied to the search; instead, abstracts, clinical notes without and abstract, and letters to the editor were reviewed to identified potentially eligible articles. Using the same keywords, we looked for articles in the searching engines of major Canadian medical journals appearing online (including nonindexed journals), and performed a manual search that included the Proceedings of the Canadian Congresses of Neurological Sciences (from 1999 to 2011), as well as the author's files, and the list of references of selected articles, cysticercosis textbooks, and position papers. Relevant information was requested from colleagues and cysticercosis experts.

Selected articles were those including original data on patients with cysticercosis diagnosed within the Canadian territory. Articles combining previously published case reports into a series of patients were included in the analysis to gather additional information, but patients were counted only once. Besides the year and the number of cases, abstracted data of selected articles included (whenever possible); the demographic profile of reported patients, the specific form of cysticercosis, clinical manifestations, and whether the disease occurred in immigrants, international travelers, or Canadian citizens who had never been abroad.

\section{RESULTS}

The search identified 49 papers, of which 21 met inclusion criteria $^{7-27}$. Fifteen of the 21 selected articles were single case reports, and the remaining six were small series describing from two to 16 patients. Most patients were reported from Ontario and Quebec (Figure). After reviewing data-and counting only once patients reported by different publications, a total of 60 patients were identified. Of these, $40(67 \%)$ were evaluated over the past 20 years.

Information on the citizenship status is available for 28 patients. Of these, only one was a Canadian citizen with history of traveling aboard (to India), and the other 27 were immigrants from cysticercosis-endemic areas (Latin America and the Caribbean 11, Europe 8, Asia 6, and Africa 1). Information on the time elapsed between immigration and symptomatic disease is available in 18 patients, and varied widely from a few months to 32 years.

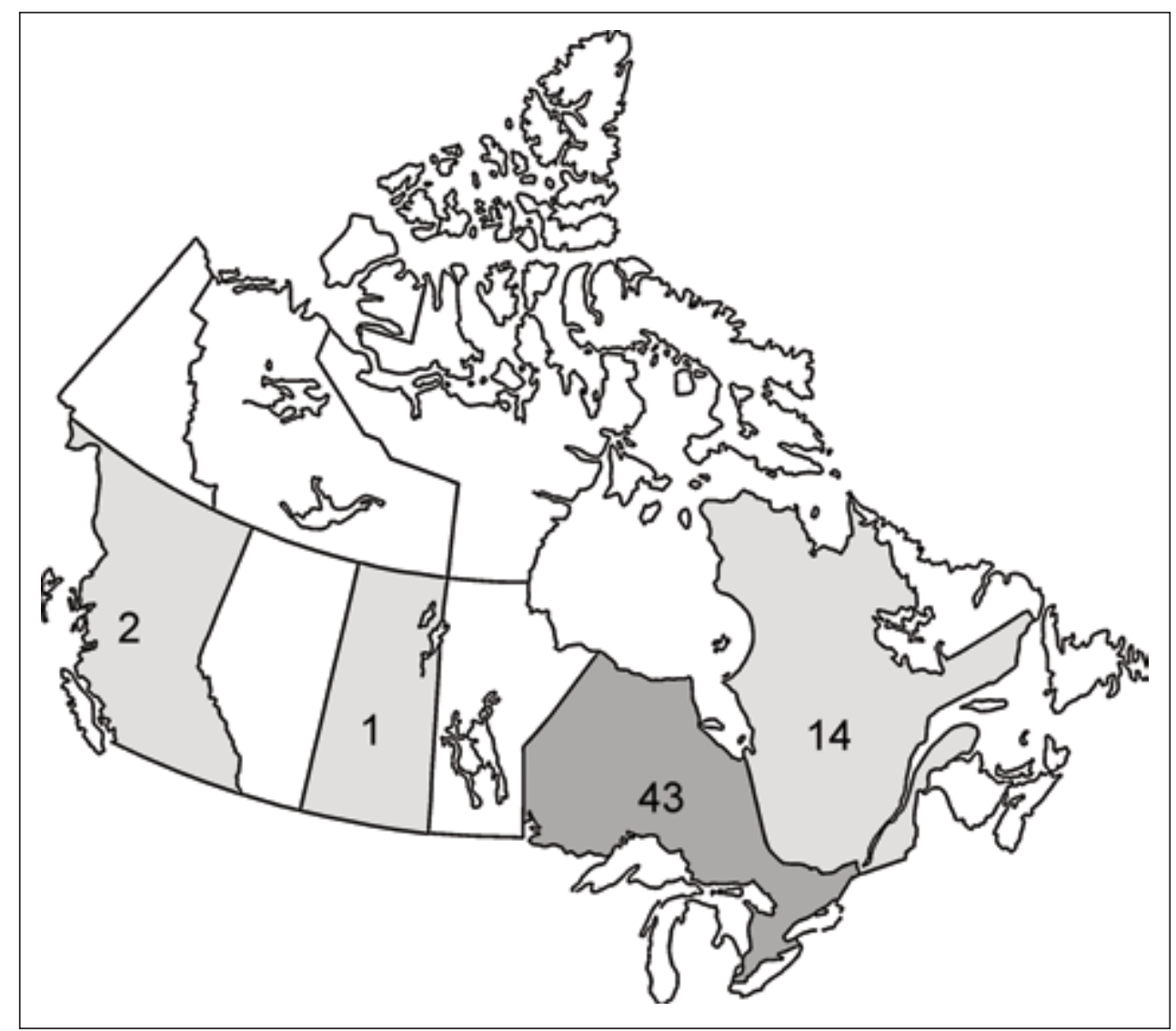

Figure: Map of Canada showing the number of reported patients per Province. 
Data on age was available in 31 patients (mean age, $33.9 \pm$ 12.6 years) and gender was available in 40 patients $(52 \%$ women). Cysticercosis affected the central nervous system (neurocysticercosis) in 55 patients. In the remaining five patients, cysticercosis affected striated muscles (with isolated involvement of extra-ocular muscles in two of them). Clinical manifestations were described in 42 of the 55 patients with neurocysticercosis. Of these, 31 had seizures, eight had evidence of intracranial hypertension, two had psychiatric manifestations, and one had recurrent episodes of meningitis. Information on the specific form of neurocysticercosis could be obtained in 37 patients. Of these, 29 had parenchymal brain cysticercosis (active cysts in 11 and calcifications in 18), four had subarachnoid racemose cysts, three had ventricular cysts, and one had spinal cysticercosis.

Stool examinations were performed in seven patients, two of whom were positive for Taenia eggs. In no case were the family or other household contacts of the patients investigated for taeniasis.

\section{Discussion}

This review suggests that the number of cases of human cysticercosis in Canada may be on the rise, since most (67\%) of all reported patients were seen during the past two decades. It was difficult to trace the first human case of cysticercosis reported from Canada, and some argued that it was a patient with two cysts removed from the Fourth ventricle in $1952^{28}$. The authors, however, considered those lesions to be colloid cysts and did not even mention the possibility of cysticercosis. Years later, that biopsy material was examined elsewhere and the pathologist concluded that the ependymal lining of the cysts resembled that of cysticercus, but the scolex could not be found; so, a definitive diagnosis of cysticercosis could not be established $^{29}$. In that paper, it was stated that The Canadian Department of Health and Welfare had no recorded case up to 1956. During those years and up to the 1970s, some case reports called attention to the occurrence of human cysticercosis among immigrants to Canada $^{7-12}$. By 1986, the first series of eight patients with CT-documented neurocysticercosis was reported from McGill University in Montreal ${ }^{13}$. As already described in the former publications, all these eight patients were immigrants from cysticercosis-endemic areas. By the end of the 20th Century, Sheth et al ${ }^{18,19}$ reported partial results of a series of 29 patients with neurocysticercosis evaluated at the University of Toronto from 1991 to 1997; the authors, however, did not give details on the citizenship of their patients. During the new millennium, a number of case reports have confirmed the sporadic occurrence of this parasitic disease in Canada, always in immigrants from endemic areas ${ }^{21-27}$. In the London Health Sciences Center (Ontario), a retrospective review of all admissions from 1994 to 2004 revealed four patients with neurocysticercosis ${ }^{22,23}$. There is also a survey performed in five different hospitals In the Niagara Region, where the authors found three possible cases of neurocysticercosis among 264 persons with epilepsy; as the diagnosis was not confirmed, those cases were not included in the present review ${ }^{30}$.

Human cysticercosis must be considered a disease mostly transmitted from person to person, and the role of infected swine is to perpetuate the infection ${ }^{31}$. While swine husbandry could be considered adequate in Canada, a number of Taenia solium carriers entering the country every year-acting like Trojan horses - may be continuously increasing the number of patients with cysticercosis without the need of infected swine. On the other hand, most Canadian doctors have assumed that when cysticercosis occurs in immigrants it is because the infection had been acquired at their country of origin. While this is probably true, it must not be forgotten that a common social phenomena observed after mass population movements is that family members usually join pioneer immigrants some years after their settlement aboard. So, it may happen that, in a given immigrant, cysticercosis was acquired while already living in Canada through a recently arrived relative infected with Taenia solium. This hypothesis is supported by the fact that some immigrants have developed symptoms related to relatively fresh infections, i.e., parenchymal brain cysticerci in the acute encephalitic phase, several years after being living in $\mathrm{Canada}^{20}$. It must be kept in mind the lesson given by the outbreak of neurocysticercosis occurring in the Orthodox Jewish community in New York City, where domestic employees (who proved to be Taenia solium carriers) recently immigrated from endemic areas, infected people for whom they worked through non-hygienic handling of food $^{32}$.

This review presents, for the first time, the situation of human cysticercosis in Canada. It has the limitation that data has not been completely reported, and some information could have been missed. Also, exact numbers on prevalence and incidence of the disease cannot be given, but it is possible that we are just seeing the tip of the iceberg as many cases could have passed undiagnosed or unreported. Only the obligatory report of cysticercosis cases will allow true knowledge of the actual burden of this parasitic disease ${ }^{33}$. In addition, compulsory search of Taenia carriers among household contacts of cysticercosis patients will allow the detection of potential sources of infection, and will reduce further spread of the disease.

\section{REFERENCES}

1. Garcia HH, Del Brutto OH. Neurocysticercosis: updated concepts about an old disease. Lancet Neurol. 2005;4(10):653-61.

2. Carabin H, Ndimubanzi PC, Budke CM, et al. Clinical manifestations associated wit neurocysticercosis: a systematic review. PloS Negl Trop Dis. 2011;5(5):e1152.

3. Serpa JA, Raviss EA, Kass JS, White AC jr. Neurocysticercosis in Houston, Texas: an update. Medicine (Baltimore). 2011;84(3): 402-5.

4. Croker C, Reporter R, Mascola L. Use of statewide hospital discharge data to evaluate the economic burden of neurocysticercosis in Los Angeles County (1991-2008). Am J Trop Med Hyg. 2010;83(1):106-10.

5. Esquivel A, Diaz-Otero F, Gimenez-Roldan S. Growing frequency of neurocysticercosis in Madrid (Spain). Neurologia. 2005;20 (3): $116-20$.

6. Cameron TWM. Sir William Osler-Parasitologist. Can Med Assoc J. 1934;30(5):553-6.

7. Owen T, Lenczner M. Generalized cysticercosis with cerebral infestation. Can Med Assoc J. 1956;75(3):213-6.

8. Lenczner M, Wollin DG. Cysticercosis: multiple infarcts and necrosis of bone. Can Med Assoc J. 1958;78(5):344-5.

9. Rechnitzer PA, Sutherland W, Drake C. Cysticercosis cerebri. Can Med Assoc J. 1959;81(2):108-9.

10. Scholten T, Pang D, Lau TS. Cysticercosis. Can Med Assoc J. 1976; 115(7):612-3

11. Ali-Khan Z, Siboo R, Meerovitch E, Faubert G, Faucher MG. Cysticercus racemosus in an eosinophilic phlegmon in the brain. Trans R Soc Trop Med Hyg. 1981;75(6):774-9. 
12. Ali-Khan Z, Chayasirisobhon S, Aubé M. Human cysticercosis: a probable case of cerebral cysticercosis with generalized subcutaneous nodular lesions. Can J Neurol Sci. 1979;6(3): 371-4.

13. Leblanc R, Knowles KF, Melanson D, MacLean JD, Rouleau G, Farmer J-P. Neurocysticercosis: surgical and medical management with praziquantel. Neurosurgery. 1986;18(4):419-27.

14. Robinson RJ, Truong DT, Mulder D, Dierness SB, Kirklin JK. Case conference. J Cardiothorac Anesth. 1989;3(3):361-8.

15. Paradis M. Selective crossed aphasia in a trilingual aphasic patient followed by reciprocal antagonism. Brain Lang. 1989;36(1): 62-75.

16. DiLoreto A, Kennedy RA, Neigel JM, Rootman J. Infestation of extraocular muscle by Cysticercus cellulosae. Br J Ophthalmol. 1990;74(12):751-2.

17. Shriqui CL, Milette PC. You drive me crazy: a case report of acute psychosis and neurocysticercosis. Can J Psychiatry. 1992;37(2): $121-4$

18. Sheth TN, Pilon L, Keystone J, Kucharczyk W. Persistent MR contrast enhancement of calcified neurocysticercosis lesions. AJNR Am J Neuroradiol. 1998;19(1):79-82.

19. Sheth TN, Lee C, Kucharczyk W, Keystone J. Reactivation of neurocysticercosis: case report. Am J Trop Med Hyg. 1999;60 (4):664-7.

20. Dylewski J, Bekhor S. Photo Quiz. Clin Infect Dis. 1996;23(4): 711,809 .

21. Brophy J, Keystone J. First seizure in a new immigrant. Paediatr Child Health. 2006;11(6):345-7.

22. Burneo JG, McLachlan RS. Neurocysticercosis in Canada: still a rare disease? Can J Neurol Sci. 2005;32(suppl 1):S67.

23. Bussiere M, Burneo J. Giant subarachnoid neurocysticercosis. Can J Neurol Sci. 2005;32(suppl 1):S67.
24. Poonja Z, Tellez-Zenteno J, Moien F. Neurocysticercosis in a 27year old male with right allien hand episodes and a single generalized seizure. Can J Neurol Sci. 2009;36(suppl 1):S46.

25. Burneo J, Plener I, Garcia HH. Neurocysticercosis in a patient in Canada. Can Med Assoc J. 2009;180(6):639-42.

26. Hajek J, Keystone J. Intraventricular neurocysticercosis managed with albendazole and dexamethasone. Can J Neurol Sci. 2009;36 (1):102-4

27. Boulos MI, Aviv RI, Lee L. Spinal neurocysticercosis manifesting as recurrent aseptic meningitis. Can J Neurol Sci. 2010;37(6): 878-80.

28. Parkinson D, Childe AE. Colloid cyst of the fourth ventricle. Report of a case of two coloid cysts of the fourth ventricle. J Neurosurg.1952;9(4):404-9.

29. White JC, Sweet WH, Richardson EP Jr. Cysticercosis cerebri. A diagnostic and therapeutic problem of increasing importance. $\mathrm{N}$ Engl J Med. 1957;256(11):479-86

30. Sanchez A, Simone B, Yarascavitch ME, Oswami R. Low frequency of neurocysticercosis in patients with epilepsy and seizure disorders in the Niagara Region, Canada: a retrospective study. Can J Infect Dis Med Microbiol. 2004;15(3):179-80.

31. Lescano AG, Garcia HH, Gilman RH, et al. Taenia solium cysticercosis hotspots surrounding tapeworm carriers: clustering to human seroprevalence but not on seizures. PloS Negl Trop Dis. 2009;3(1):e371

32. Schantz PM, Moore AC, Muñoz JL, et al. Neurocysticercosis in an Orthodox Jewish community in New York City. N Engl J Med. 1992;327(10):692-5

33. Roman G, Sotelo J, Del Brutto OH, et al. A proposal to declare neurocysticercosis an international reportable disease. Bull WHO. 2000;78(3):399-406. 